\title{
Evolución de las tecnologías de prefabricación aplicadas a la arquitectura escolar
}

\author{
Evolution of prefabricated technologies applied \\ to building schools
}

\section{O. Pons $^{(*)}$}

\section{RESUMEN}

En los últimos diez años se han construido centenares de escuelas con sistemas prefabricados en toda España. Por ejemplo, más de 200 escuelas han sido industrializadas con éxito desde 2002 en Cataluña. Se trata de edificios docentes modernos que han sido reconocidos por su arquitectura, por su relación con el entorno, por sus espacios educativos... Este artículo tiene el objetivo de analizar estas escuelas, así como las interesantes tecnologías de prefabricación con las cuales se han construido. La elaboración de este texto se basa en el trabajo que el autor del artículo ha realizado en sus tres años de doctorado, que ha culminado con la tesis "Arquitectura escolar prefabricada en Cataluña".

Este artículo se estructura en cuatro partes: un estudio general de la historia de la arquitectura escolar prefabricada en España, un análisis de la industrialización de escuelas en el pasado, un análisis de la prefabricación de centros en la actualidad y unas conclusiones sobre el futuro de estas tecnologías de prefabricación.

Las tecnologías que se estudian en este texto son la aplicación renovada de unos sistemas prefabricados que ya existían previamente. En el período de crisis actual, ¿no es un buen momento para renovar el sector y construir con tecnologías más avanzadas como las que se presentan en este artículo?

Palabras clave: tecnologías de prefabricación, construcción industrializada, sistemas constructivos, arquitectura escolar, historia de la prefabricación.

\section{SUMMARY}

In the past ten years, a lot of school buildings have been built using prefabricated systems all over Spain. For example, more than 200 schools have been successfully industrialized since 2002 in Catalonia. These are modern schools that have been recognized for: their well designed architecture, their respectful relationship with their environs, their education spaces... This article aims to analyze these centers, along with the interesting technologies used to build them. This text is based on the research that the author carried out during his $P h D$, before he wrote his thesis "Prefabricated school buildings in Catalonia".

This article has four parts: a general study of the history of Spanish prefabricated school buildings, an analysis of former industrialized school buildings, a study about current prefabricated schools and the conclusions about the future of the prefabricated technologies used in these schools.

The building systems studied in this text are an updated version of similar former technologies. The current crisis in construction could be an ideal moment to reflect on the need to design and build employing a more up-to-date, innovative construction technology, like the ones analyzed in this article.

Keywords: prefabricated technologies, industrialized construction, building systems, school buildings, prefabrication history. 


\section{INTRODUCCIÓN}

Actualmente la prefabricación sigue siendo una opción minoritaria en la construcción de edificios. No obstante, en los últimos años el uso de sistemas de fabricación en taller ha aumentado en nuestro país. Un caso paradigmático es el de los centros docentes: desde finales de los años 1990 se han prefabricado centenares de escuelas. La razón principal ha sido la grave necesidad de plazas escolares que ha habido en estos años en nuestro país, sobre todo de Centros de Educación Infantil y Primaria (CEIP). Para solucionar este déficit algunas Comunidades Autónomas han industrializado escuelas. Por ejemplo, en Cataluña, desde el 2002 se han construido más de 200 centros docentes mediante tecnologías de prefabricación, de los cuales dos tercios han sido CEIP.

Se puede considerar que la mayoría de estas escuelas han sido un éxito. Muchos profesionales que han participado en su proyecto y obra están satisfechos del resultado y han repetido la experiencia. Los arquitectos hemos podido integrar los edificios en su entorno, proyectar los espacios más indicados para cada uso... Las industrias han desarrollado y adaptado sus sistemas. Y la administración ha llegado a finalizar escuelas en sólo 8 meses, incluyendo el proyecto, la fabricación y la puesta en obra. En este artículo se estudiará el caso de estos centros docentes. Son edificios escolares "prefabricados", es decir, que han sido producidos en una factoría y se han montado posteriormente en la obra. Se han construido con "sistemas": conjunto de elementos prefabricados ordenados racionalmente con leyes de interdependencia. Estos sistemas se pueden clasificar según la parte del edificio que resuelven:

- Sistemas cerrados que resuelven el conjunto del edificio.

- Sistemas abiertos que resuelven, como mínimo, la estructura y la fachada, los cuales se complementan con otros sistemas que solucionan el resto del edificio.

También se pueden clasificar según el peso:

- Sistemas ligeros: con estructura metálica o estructura mixta.

- Sistemas pesados: con estructura de hormigón armado.

Estos sistemas son "tecnologías": conjunto de conocimientos y medios técnicos aplicados a la construcción. Son "tecnologías de prefabricación" que forman parte de la "construcción industrializada", un término genérico que actualmente engloba: nuevos materiales, nuevas aplicaciones, tecnologías pretéritas renovadas.
En este texto primero se analizará, de forma general, la historia de la arquitectura escolar prefabricada en nuestro país. Después se hará un análisis de los principales sistemas prefabricados utilizados para construir centros en el pasado y en la actualidad. Finalmente se extraerán unas conclusiones sobre el futuro de estas tecnologías.

Este artículo se basa en la investigación que el autor ha realizado en sus tres años de doctorado, que ha culminado con la tesis "Arquitectura escolar prefabricada en Cataluña" (1). Durante el doctorado el autor investigó la arquitectura escolar industrializada en España, y, a partir de esta búsqueda, elaboró este artículo. Esta investigación se llevó acabo en Barcelona, por esta razón la mayoría de datos y ejemplos del texto son de esta zona.

Este hecho se acentúa en el estudio de los años 2000, periodo en la cual, hasta el momento, una gran parte de las escuelas prefabricadas se han montado en Cataluña.

\section{LA ARQUITECTURA ESCOLAR PREFABRICADA EN ESPAÑA}

Las tecnologías de prefabricación que se utilizan en la actualidad son deudoras de otros sistemas constructivos utilizados en el pasado. En nuestro país, la historia de la prefabricación de escuelas ha tenido periodos tardíos y desplazados, en relación con la prefabricación de otro tipo de edificios y en relación con la prefabricación en otros países. Podemos distinguir 4 periodos principales:

\subsection{Antes de 1970}

Las primeras experiencias en la prefabricación de escuelas fueron proyectos puntuales de los años 1950 y 1960. Por ejemplo, en 1955 el arquitecto R. García con la empresa Durisol construyó 5 centros mediante sistemas industrializados en el Campo de Gibraltar (Fig. 1). Posteriormente, coincidiendo con la construcción mediante sistemas prefabricados de polígonos de viviendas, se industrializaron escuelas utilizando los mismos sistemas que en esos polígonos. Por ejemplo, en el barrio de Bellvitge de l'Hospitalet, Barcelona, se prefabricó la escuela "Pare Enric d'Ossó" en 1967 con el sistema Estiot (3). En aquellos años la economía española se estaba recuperando lentamente de una situación de subdesarrollo, la cual había debilitado gravemente el sector industrial.

En consecuencia, la mayoría de edificios se construyeron con técnicas y materiales locales, con una construcción artesana y con la única excepción de algunas fábricas de pequeños elementos. En cambio, durante esos 
mismos años, en muchos países europeos se diseñaban nuevos sistemas de fabricación en taller con los cuales se construyeron gran cantidad de edificios (4).

\subsection{Los años 1970}

La década de 1970 es la primera etapa en la que hay una importante prefabricación de escuelas. Son años con un importante déficit de plazas escolares, un problema que se arrastraba del pasado y que se acentuó con el éxodo de las zonas rurales hacia las ciudades con industrias. Para ampliar el número de plazas escolares el gobierno tomó medidas como los concursos derivados de los "Pactos de la Moncloa".

Por ejemplo, en un concurso de 1977 se adjudicaron 191 centros docentes para prefabricar en 23 provincias españolas. En aquellos años se prefabricaron centenares de centros para todas las edades mediante unas veinte industrias, las cuales trabajaron fieles con un mismo equipo técnico para hacer edificios escolares en todo el territorio. Eran "proyectos tipo" que se repetían en cualquier punto del país, sin ninguna concesión al lugar, a la trama urbana o al paisaje. Por ejemplo, en 1978 "Nadeco" prefabricó diversas escuelas "tipo" en Sevilla (Fig. 2).

Aunque en este periodo se prefabricaron gran cantidad de escuelas, se construyeron más edificios docentes "tipo" con técnicas no industrializadas. En estos años también empezó la industrialización de aularios de uso temporal, también llamados barracones o caracolas, la cual sigue vigente en la actualidad (6).

\subsection{Los años 1980 y 1990}

En los años 1980 disminuyó drásticamente la prefabricación de escuelas. Por un lado, casi la totalidad de prefabricadoras habían suspendido sus actividades, a causa de las crisis económicas de finales de 1970. Además, las competencias en materia de educación se fueron traspasando a las Comunidades Autónomas, y se abandonaron medidas previas como los proyectos "tipo". En este periodo los centros docentes existentes ofrecían suficientes plazas escolares, aunque muchos estaban desfasados para la educación del momento y hubieron necesitado ser rehabilitados.

En ambas décadas 1980 y 1990 se construyeron menos escuelas. Para los centros escolares de carácter temporal siguieron utilizándose los módulos metálicos "Caracola". Pero en las escuelas de carácter permanente se utilizaron mayoritariamente técnicas artesanales y pequeños elementos (8). Sólo alguna escuela fue construida con sistemas industrializados, como por ejemplo el CEIP
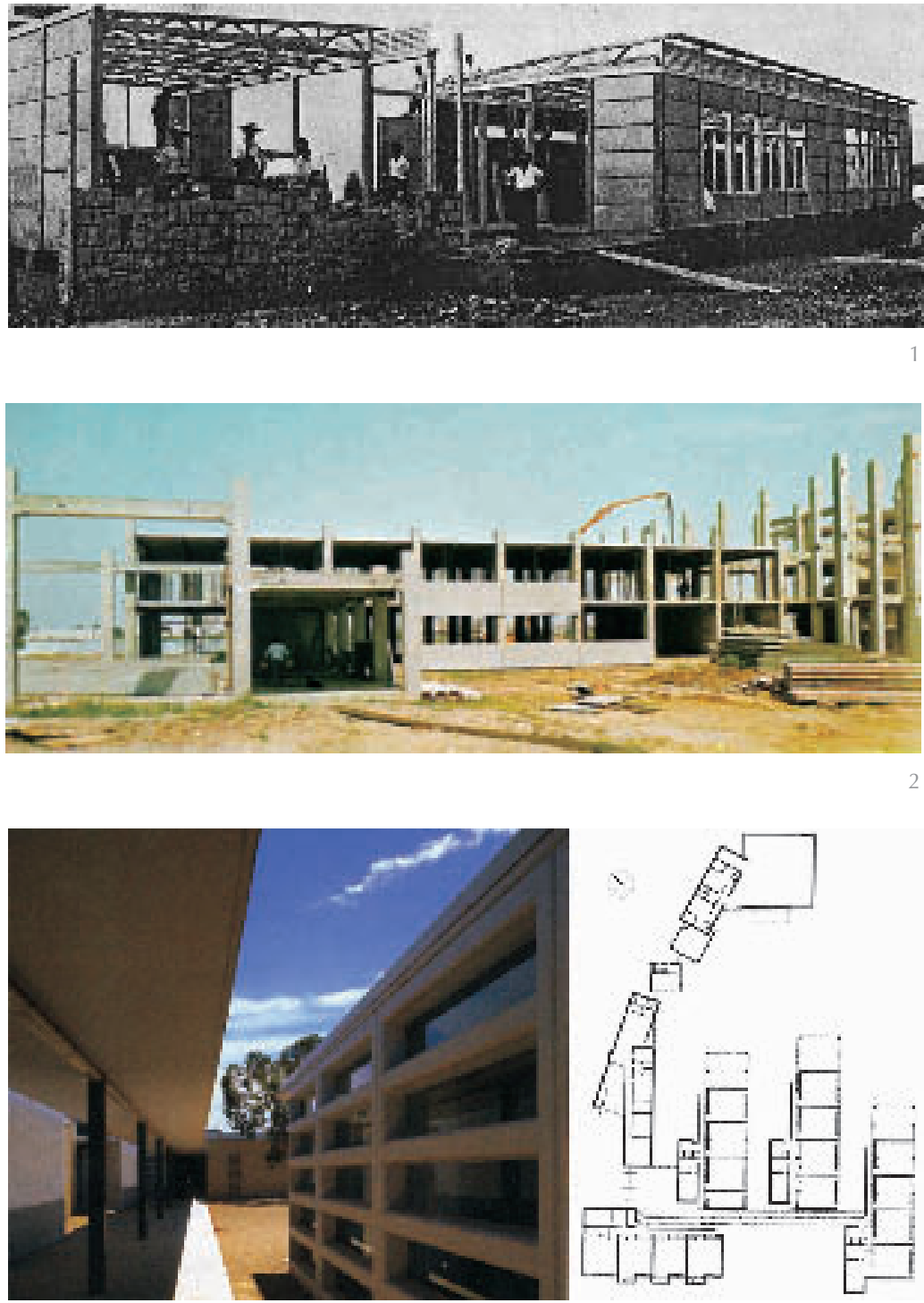

Riumar en Deltebre, Cataluña, que en 1995 construyeron los arquitectos M. Ruisánchez y X. Vendrell con la industria "Prefabricados Pujol" (Fig. 3).

\subsection{Los años 2000}

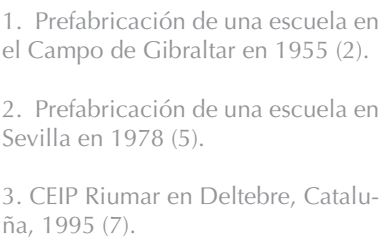

En la década actual han vuelto a construirse gran cantidad de escuelas con sistemas prefabricados. Al principio, fueron años de prosperidad económica, en los cuales hubo movimientos migratorios importantes: nuestro país recibió inmigrantes de otros países como mano de obra barata, al mismo tiempo que muchas familias prósperas se trasladaron a vivir de las grandes ciudades a pueblos de alrededor. En consecuencia, hubo necesidad de plazas escolares en municipios que hasta el momento habían tenido excedente. Algunas Autonomías, como Cataluña, probaron la construcción de centros permanentes en sólo 6 u 8 meses mediante sistemas 


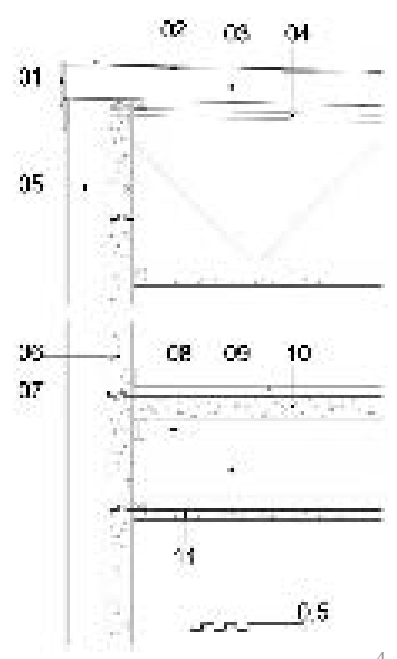

LEYENDA:

01. Remate de la cubierta con chapa grecada de acero.

02. Lámina asfáltica.

02. Lámina asfáltica.

03. Chapa doblada de acero.

04. Celosía de cubierta de acero.

05. Pilares del edificio: HEB 200 de acero pintados.

06. Fachada de placas "Durisol FHC"

06. Fachada de

$150 \times 50 \times 10$.

07 . Junta estanca de doble fase con sellado interior.

08. Viguetas de forjado cada $1,5 \mathrm{~m}$ de perfiles IPN.

perfiles IPN.

09. Vigas de forjado de perfiles IPN

10. Forjado de placas "Durisol T10"

$149 \times 50 \times 10$.

11. Cielo raso de placas de "Durisol AP4" $150 \times 50 \times 4.08$ constructivos prefabricados. En el caso de Cataluña, la medida se consideró un éxito por todos los profesionales e instituciones implicadas y más de 200 centros docentes han sido industrializados hasta hoy. Estos centros, a diferencia de los construidos en 1970, se han definido mediante proyectos de arquitectura exclusivos para cada centro (9).

\subsection{Resumen}

La historia de la prefabricación de centros docentes en España ha tenido períodos muy diferenciados:

- Los años 1950 y 1960, cuando hubo las primeras experiencias de prefabricación de escuelas, que fueron anecdóticas y dispersas.

- Los años 1970, cuando se prefabricaron centenares de centros "tipo" en todo el país.

- Los años 1980 y 1990, con una disminución radical de la prefabricación de escuelas de carácter permanente, aunque se produjeron centros temporales.

- Los años 2000, en los cuales se han prefabricado gran cantidad de escuelas con proyectos individuales, la mayoría de los cuales en la Comunidad Autónoma de Cataluña.

En las dos partes siguientes del artículo se estudiarán los dos períodos en los cuales la prefabricación ha sido máxima: en los años 1970 y los años 2000.

\section{LAS TECNOLOGÍAS PREFABRICADAS DE LOS AÑOS 1970}

En estos años se utilizaron principalmente 6 sistemas distintos para la prefabricación de escuelas, todos ellos sistemas cerrados, de los cuales la mitad eran ligeros y la otra mitad eran sistemas pesados. A continuación se describen estas 6 tecnologías ordenadas cronológicamente según su fecha de inicio.

Se explican las aplicaciones del sistema, las características constructivas, el tejido industrial y los procesos de fabricación y montaje.

\subsection{Sistema de estructura metálica modulada y cerramientos de paneles de hormigón y fibras}

Esta tecnología la fabricó la empresa "Durisol" de 1952 a 1979 cerca de Barcelona (10). Las primeras escuelas construidas con este sistema fueron las del Campo de Gibraltar, que se comentan en el punto "2.1." de este artículo. En los años setenta fue cuando se construyeron más escuelas.
En Cataluña, se prefabricaron centros de Educación General Básica (EGB) - 24.000 m²-, Institutos, universidades... Sólo con el concurso de 1978 derivado de los "Pactos de la Moncloa", el Ministerio de Educación y Ciencia (MEC) construyó $18.000 \mathrm{~m}^{2}$ de aularios repartidos entre Alicante, Jaén, Málaga y Valencia.

El sistema se componía de: a) una estructura metálica porticada modulada a 1,5 m en planta; b) unas placas macizas de hormigón y fibras que solucionaban forjados, fachadas, tabiques, falsos techo (Fig. 4).

Las uniones entre elementos metálicos eran atornilladas y, por lo tanto, su ejecución era rápida y reversible, como las uniones entre elementos de cerramiento, que eran encajadas en seco.

En cambio, el forjado era laborioso porque se tenían que hormigonar los espacios entre placas y una capa superior. El proceso de montaje duraba de 2 a 3 meses. En parte, consistía en la colocación de elementos prefabricados, como era el caso de la estructura, la fachada y las divisiones interiores.

En cambio, las otras partes del edificio se ejecutaban in situ como en cualquier otro edificio.

\subsection{Sistema de estructura metálica modulada y cerramientos por componentes}

Desde 1969 hasta 1973 la empresa barcelonesa "Modulteu" intentó implantar en nuestro país un sistema industrializado derivado del sistema británico "CLASP" (11). El arquitecto Carlo Testa fue el encargado de adaptar el sistema inglés a la realidad económica española de los años 1970. Aunque el planteamiento técnico y empresarial era prometedor, todo terminó como una experiencia fracasada. Sólo duró cuatro años, en los cuales se prefabricaron una decena de edificios en Barcelona y un hotel en Argelia. Entre ellos se hicieron 6 centros docentes, con una superficie total de $15.152 \mathrm{~m}^{2}$. Este sistema estaba formado por una estructura de acero porticada isostática, que estaba modulada a $30 \mathrm{~cm}$ en planta y altura.

En las vigas metálicas se apoyaban unas placas de hormigón ligero y unos paneles de fachada de hormigón armado con aislamiento en su interior. La mayoría de uniones eran encajadas o atornilladas, por lo tanto eran reversibles (12). Sólo las placas de forjado se ejecutaban con hormigón vertido en obra. La construcción la hacían en unos 3 meses unos montadores especializados: colocaban la estructura y el cerramiento de la fachada mediante una grúa torre. Las otras partes se construían en la obra de forma más o menos artesanal (Fig. 5). 


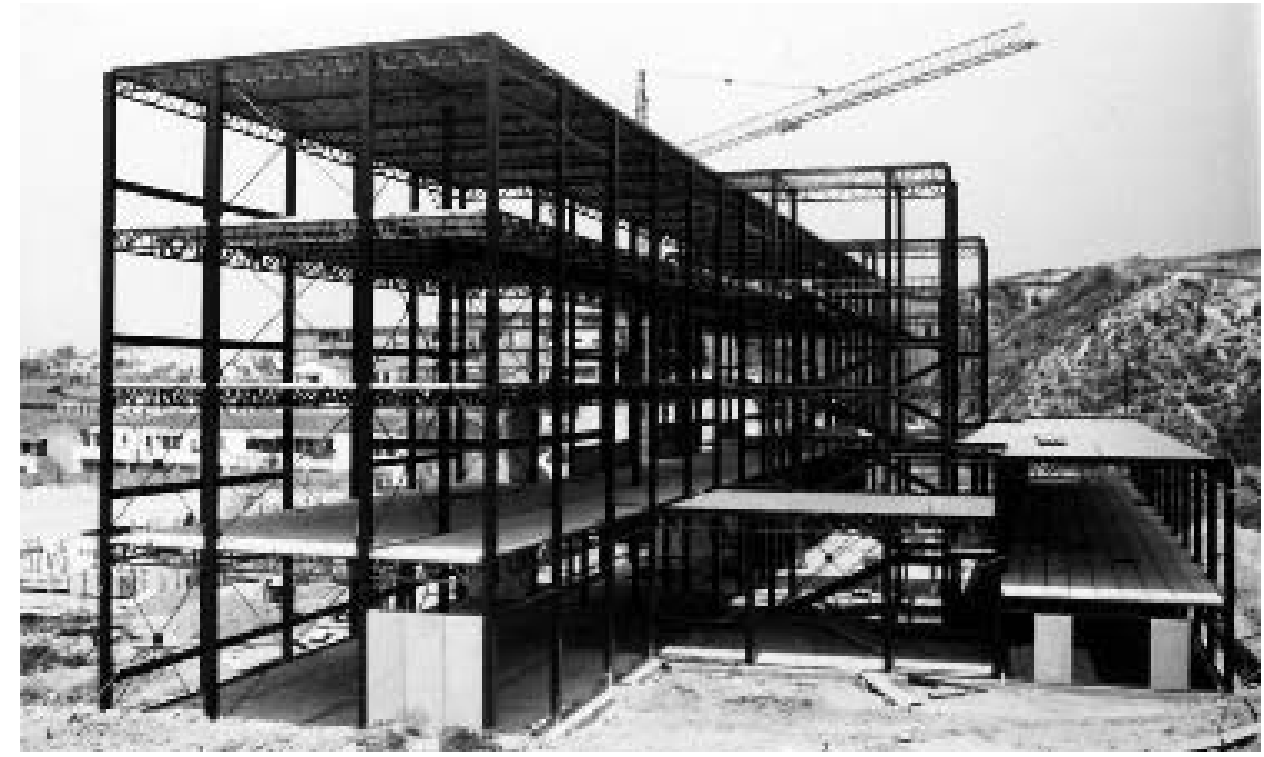

\subsection{Sistema de muros portantes tricapa, pórticos y placas de forjado de hormigón prefabricado}

El inicio de este sistema fue en 1971, cuando la empresa "Cidesa" empezó a producir edificios en sus plantas prefabricadoras. Previamente, había industrializado edificios de viviendas a pie de obra. En sus fábricas -en Madrid y en Cataluña - prefabricó edificios según el sistema Larsen \& Nielsen, el Spiroll... Construyó gran cantidad de edificios docentes en Alicante, Cataluña, Valencia... La mayoría de ellos fueron aularios, por ejemplo, en Cataluña se prefabricaron $8.000 \mathrm{~m}^{2}$ (13). El sistema estaba compuesto por una estructura prefabricada de hormigón de muros portantes y losas alveolares. Todas las uniones se hormigonaban en la obra. Los muros exteriores también resolvían la fachada. Tenían 3 capas: una capa interior portante de hormigón armado de $12 \mathrm{~cm}$, una capa intermedia de Poliestireno Expandido (EPS), y una capa exterior de hormigón armado de 5 $\mathrm{cm}$ con nervios (Fig. 6). Las juntas entre paneles se resolvían mediante hormigón vertido en la obra en el interior y un diafragma de neopreno en el exterior. El montaje se podía completar en sólo 2 meses, tanto la colocación de la estructura y la fachada, como la ejecución in situ de las otras partes del edificio. Había otras empresas con tecnologías similares, como "Construcciones Colomina".

\subsection{Sistema de muros portantes tricapa y placas de forjado de hormigón prefabricado}

En 1972 la empresa "Modulbeton" empezó a prefabricar una versión del sistema danés "Jespersen", que utilizó durante doce años. En sus fábricas de Cataluña y Madrid produjo más de un centenar de edificios, de los cuales más de cincuenta fueron centros docentes para Barcelona, Huesca, Madrid, Murcia... (14).

El sistema "Modulbeton" permitía construir estructuras y fachadas de elementos de hormigón armado prefabricado, que seguían el módulo de $90 \mathrm{~cm}$ en planta. Las estructuras estaban formadas por muros portantes, pórticos y forjados de losas alveolares. Todas las uniones entre elementos estructurales eran mediante el vertido de hormigón in situ. Los muros portantes y de arriostramiento exteriores definían el cerramiento de fachada, que era muy similar al caso anterior "3.3". Eran muros prefabricados de varias capas: una interior portante de hormigón armado de 10 a $15 \mathrm{~cm}$ de espesor, una intermedia de EPS y una capa exterior de hormigón armado de $8 \mathrm{~cm}$. Las juntas entre paneles se resolvían mediante hormigón vertido en la obra en el interior y un diafragma de neopreno en el exterior (Fig. 7). El montaje de la estructura y

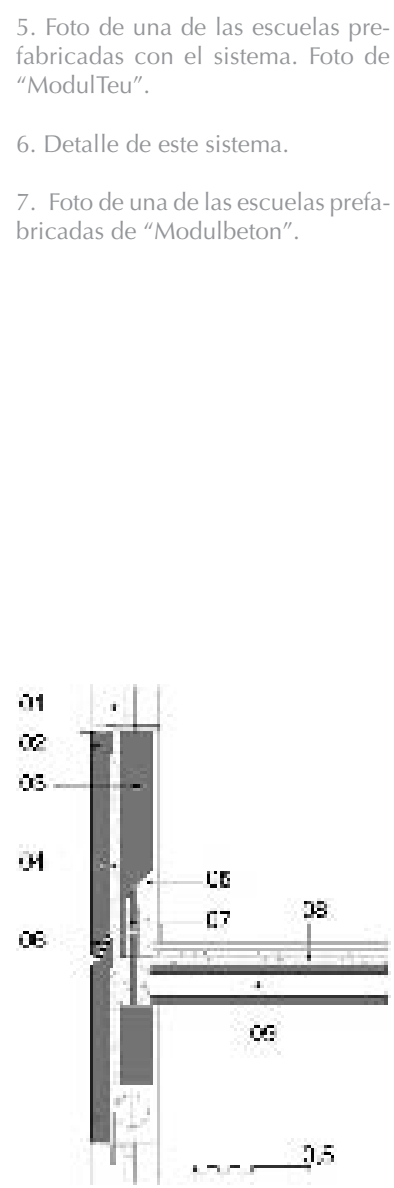

LEYENDA:

01. Carpintería de aluminio con vidrio de una hoja.

02. Hoja exterior de acabado del panel prefabricado de hormigón de $5 \mathrm{~cm}$. 03. Hoja portante del panel prefabricado de $12 \mathrm{~cm}$.

04. Aislamiento continuo del pane de $1 \mathrm{~cm}$

05. Hormigón vertido in situ. 06. Encabalgamiento para junta horizontal de fachada.

07. Conectores entre paneles.

08. Capas de hormigón para nivelación y pavimento.

09. Forjado de placas alveolares prefabricadas.

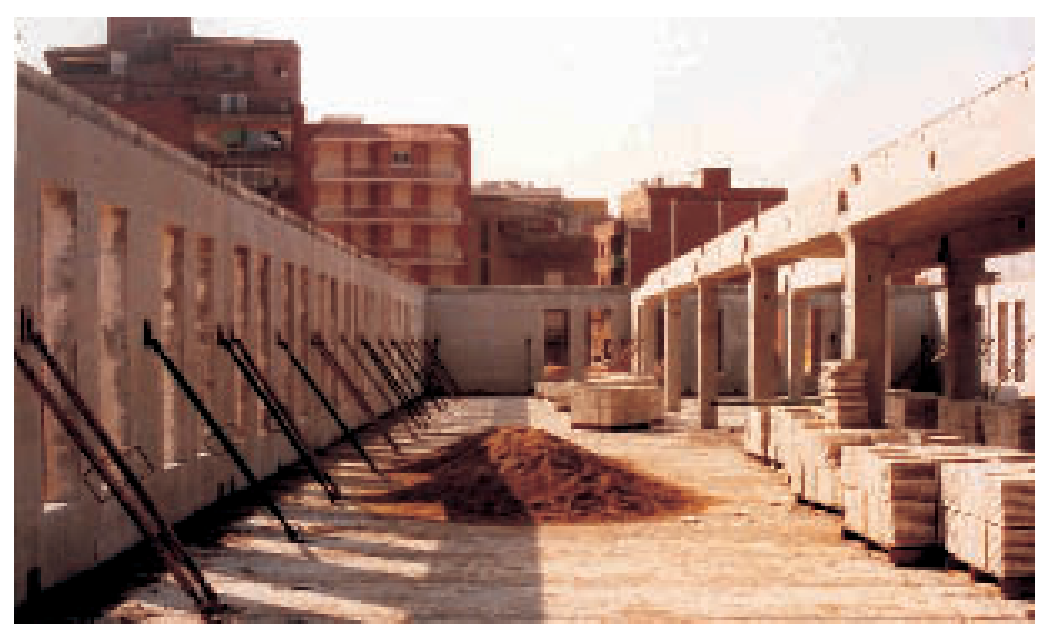




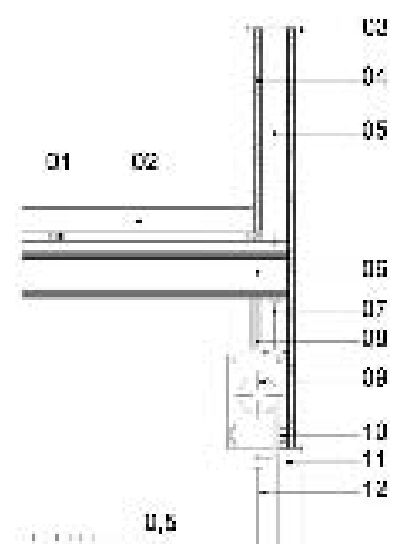

LEYENDA:

01. Rastreles de cubierta con perfiles metálicos.

02. Planchas nervadas de fibrocemento.

03. Coronación de plancha de acero lacada blanca.

04. Panel sándwich de $3 \mathrm{~cm}$ de espesor. 05. Estructura de la coronación de perfiles metálicos.

06. Forjado de placas alveolares prefabricadas.

prefabricadas.
07 . Jácena, por ejemplo IPN 240.

08. Trasdosado de placas de yeso de 4 $\mathrm{cm}$ de espesor.

09. Persiana enrollable de plástico.

10. Subestructura de la fachada de perfiles metálicos.

perfiles metálicos.
11. Jambas de plancha metálica acabada lacada blanca.

12. Carpintería de aluminio con vidrio de una hoja.
8. Detalle de este sistema.

9. Foto de una de las escuelas prefabricadas, Departamento de Educación (DE).

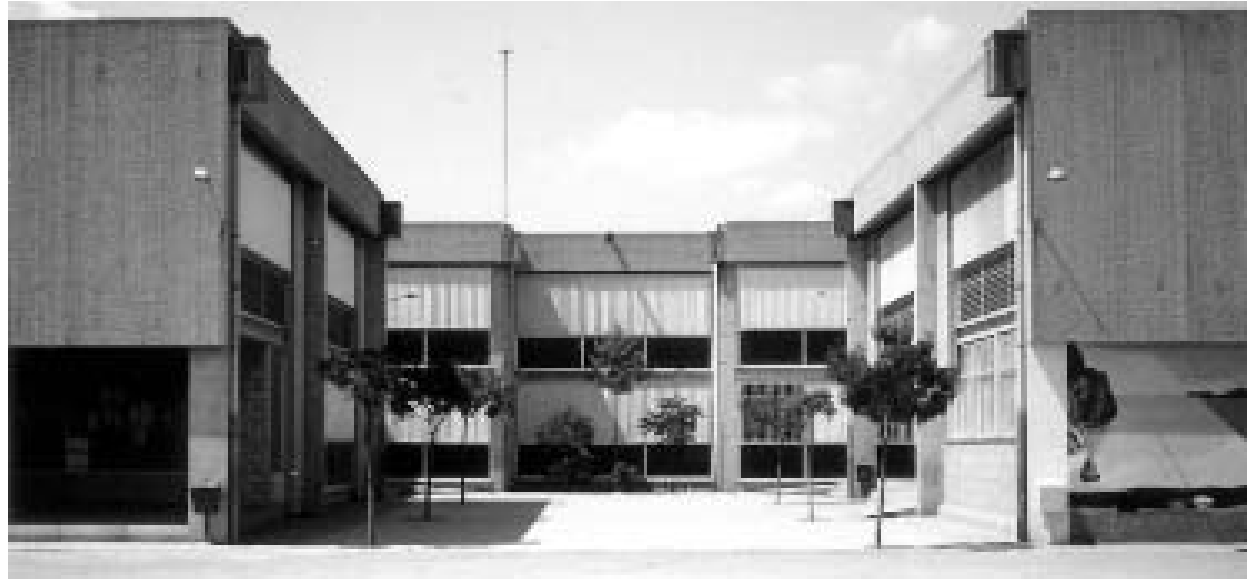

la fachada prefabricadas, junto con la ejecución de las otras partes en la obra, lo resolvía la empresa prefabricadora en 3 meses.

\subsection{Sistema de estructura metálica modulada y cerramientos de paneles sándwich}

El grupo empresarial madrileño "Sanqui" construyó escuelas con este sistema en la década de 1970. Este grupo prefabricó todo tipo de edificios en España, África, Sudamérica y Asia. En España, desde 1974 a 1977 se ejecutaron centenares de edificios docentes, una quincena de los cuales en Cataluña (15).

Estos edificios se construyeron con un sistema propio, formado por una estructura metálica de pórticos de acero con forjados de losas alveolares. El cerramiento era de paneles de acero sándwich lacado con aislamiento en el interior, los cuales se atornillaban a una subestructura de acero. Estos paneles se colocaban en vertical y tenían un ancho de $90 \mathrm{~cm}$, que podía modular en planta el edificio. La mayoría de uniones y juntas se ejecutaban en seco, como las uniones atornilladas de la estructura de acero y de los paneles sándwich (Fig. 8). El montaje era sencillo y lo hacían en 2 ó 3 meses los montadores de la empresa, colocando la estructura y el cerramiento de la fachada prefabricados y construyendo en el lugar el resto del edificio.

La empresa "Dragados" prefabricó escuelas de carácter permanente con un sistema similar en los 1970, aunque su actividad principal fue la prefabricación de los módulos "Caracola", utilizados para aularios de carácter temporal.

\subsection{Sistema de pórticos, placas de forjado y paneles de fachada de hormigón prefabricado}

Aunque en los años 1950 había sistemas similares en Europa, esta tecnología se introdujo en España en los años 1970. Fueron empresas como "Balsa", "Conspania", "Nadeco" y "Obrascón" con sede en Madrid; y "SpanDeck" con fábrica en Cataluña. Con este sistema se construyeron muchos edificios escolares. Por ejemplo, en el año 1978, se construyeron más de treinta centros docentes (Fig. 9).

El sistema, que fabricaba cada empresa con sus particularidades, consistía en una estructura y fachada prefabricadas de hormigón. La estructura era de pilares, vigas y forjados de losas alveolares. Las uniones de los paneles de fachada eran atornilladas o soldadas, pero las uniones estructurales eran hormigonadas in situ. La fachada era de paneles de hormigón armado o de placas alveolares. Las juntas entre paneles se resolvían mediante un sellado con masillas y unos sistemas de drenaje de seguridad.

El montaje de una escuela también podía reducirse a 2 meses, incluyendo la colocación de la estructura y la fachada prefabricadas y la ejecución in situ de las otras partes del edificio.

Hubo muchas variantes de este sistema. Por ejemplo, las empresas "Cutillas" y "Grau Salas" construyeron edificios con estructura prefabricada de hormigón y fachadas de bloque de hormigón y paneles sándwich.

\section{LAS TECNOLOGÍAS PREFABRICADAS DE LOS AÑOS 2000}

Los sistemas constructivos que se han utilizado en la década actual para la prefabricación de escuelas también se podrían clasificar principalmente en 6 tipos distintos. Estos sistemas son abiertos, la mitad de los cuales son ligeros y la otra mitad pesados. A continuación se describen estas 6 tecnologías ordenadas según el número de centros que se han prefabricado con cada sistema en los últimos diez años, empezando con la tecnología más utilizada. 


\subsection{Sistema de pórticos, placas de forjado y paneles de fachada de hormigón prefabricado}

Esta es una tecnología vigente, resultante de la evolución de los sistemas utilizados en los años 1970, que se estudian en el punto "3.6". Actualmente hay muchas empresas prefabricadoras que producen edificios docentes con este sistema, por ejemplo: "Hormipresa", "Mdm", "Planas", "Pujol", "Selfhor", "Tecnyconta"... En Cataluña, desde 2002 a 2006 se construyeron $79.000 \mathrm{~m}^{2}$ de CEIP públicos. Este sistema tiene componentes prefabricados de hormigón semejantes a los de sus predecesores.

La estructura es de pilares, vigas y losas alveolares; los cerramientos de fachada son de paneles autoportantes.

Las uniones estructurales se resuelven en su mayoría con hormigón vertido en la obra, como, por ejemplo, la unión entre jácena y placas alveolares de la figura adjunta (Fig. 10.). Pero en la actualidad está aumentando el uso de uniones atornilladas con elementos auxiliares de acero. Por ejemplo, los "pies de pilar", que unen los pilares con la cimentación mediante tornillos y mortero de alta resistencia y baja retracción. En los años setenta, ya se habían desarrollado en el extranjero uniones semejantes entre pilares, entre pilares y vigas... (Fig. 11), algunas de las cuales se siguen utilizando en la actualidad junto con nuevas soluciones (17).

Las uniones entre los paneles de fachada y la estructura se resuelven con fijaciones especializadas atornilladas a los forjados. Las juntas entre paneles se sellan con silicona por el exterior, teniendo en el interior un sistema de drenaje de seguridad (18). Este sistema prefabricado sólo resuelve en fábrica la estructura y el cerramiento de fachada. Las otras partes del edificio se ejecutan en la obra por parte de industriales externos.

La fabricación de los componentes de este sistema requiere maquinaria más o menos especializada: moldes para pilares; moldes para vigas armadas y pretensadas; moldes para escaleras; pistas para paneles y muros; una central hormigonera; puentes grúa... Estas máquinas necesitan un control y un trabajo manuales, excepto los trenes automatizados para tratamientos de acabado, como el lavado con chorro de agua o el pulido.

El proceso de fabricación de un CEIP con este sistema puede durar de 20 a 25 días hábiles. El montaje de la estructura y de la fachada lo realizan montadores especializados mediante grúas móviles. En el caso de un CEIP, el montaje de la estructura y del cerramiento de la fachada puede durar unos
20 días hábiles. Una posible secuencia de montaje sería:

1. Los elementos llegan a la obra mediante camiones normales o tipo "góndola".

2. Se empotran los pilares en el terreno, que son de una sola altura, mediante uniones en cáliz, envainadas o tipo "pie de pilar".

3. Se montan los forjados, empezando por el inferior y construyéndolos uno por uno: a) se apoyan las jácenas en las ménsulas; b) se apoyan las placas alveolares en las jácenas; c) se arman y hormigonan las uniones entre placas y vigas, los macizados y una capa superior.

4. Se fijan los anclajes de los paneles de fachada con la estructura y se sellan las juntas.

5. Otros industriales finalizan las otras partes de la obra: interiores, instalaciones...
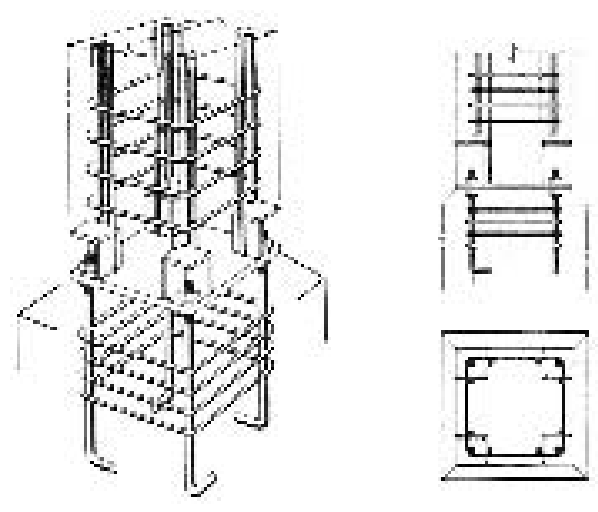

Un ejemplo de CEIP prefabricado con esta tecnología es el "Ca n'Alzamora" de Rubí, Barcelona (Fig. 12). Éste fue promovido en 2005 por el Departamento de Educación de Cataluña ("DE"), diseñado por F. Bordes y prefabricado por "Planas". Sus $2.847 \mathrm{~m}^{2}$ fueron fabricados y montados en 8 meses. La estructura estaba formada por pilares cuadrados de $50 \times 50 \mathrm{~cm}$ de 3 niveles de altura, vigas de hasta $850 \times 50 \times 55 \mathrm{~cm}$ y losas alveolares de hasta $1.200 \times 110 \times 25 \mathrm{~cm}$ con una capa superior de hormigón armado de $5 \mathrm{~cm}$.

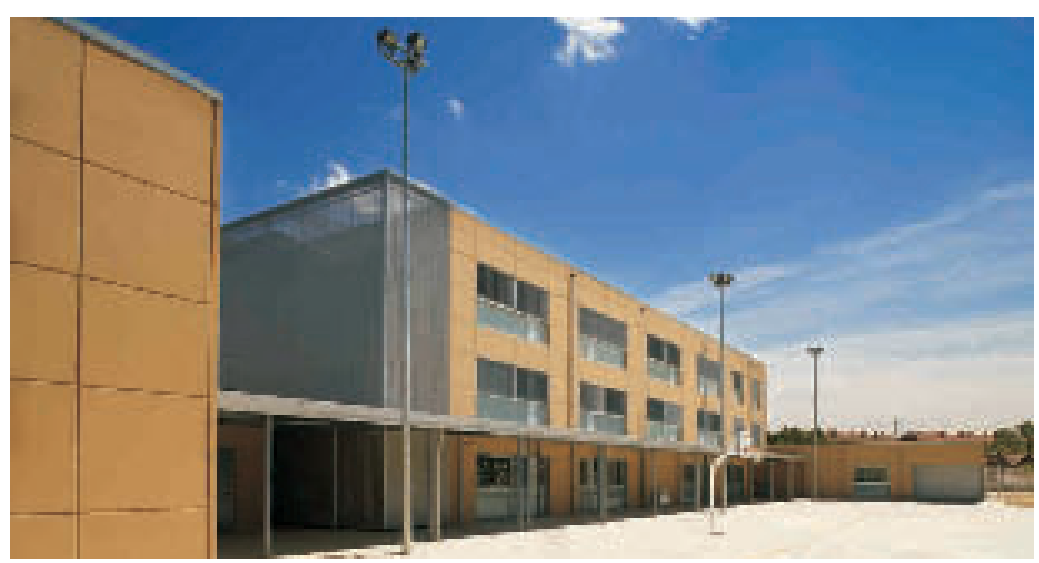

10. Detalle de este sistema.
11. Detalle del "pie de pilar" de 1973 (16).

12. Foto de una de las escuelas prefabricadas. Foto cedida por "GISA" e "Imanagest".

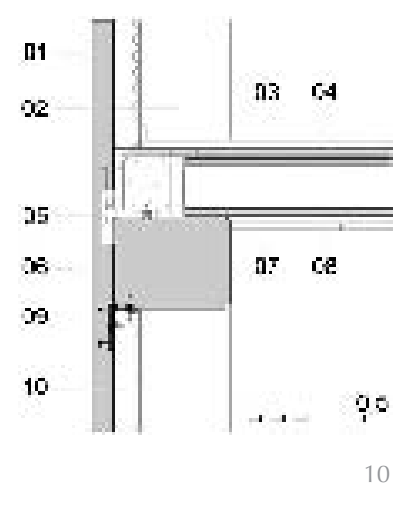

LEYENDA:

01. Panel prefabricado de hormigón de $10 \mathrm{~cm}$.

02. Pilar prefabricado de hormigón de $50 \times 50 \mathrm{~cm}$.

03. Capa superior de hormigón in situ de $5 \mathrm{~cm}$.

04. Pavimento encima de capa de nivelación. 06. Jácena en parte prefabricada y en parte vertida en obra, con un descuelgue de $55 \mathrm{~cm}$.

07. Placa alveolar pretensada de 20 $\mathrm{cm}$ de canto.

08. Falso techo de placas de fibras.

09. Anclaje metálico de retención del panel.

10. Trasdosado de perfiles metálicos y placas de yeso.
05. Anclaje metálico portante del panel. 


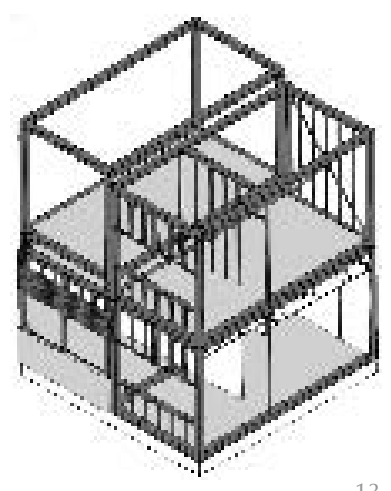

13

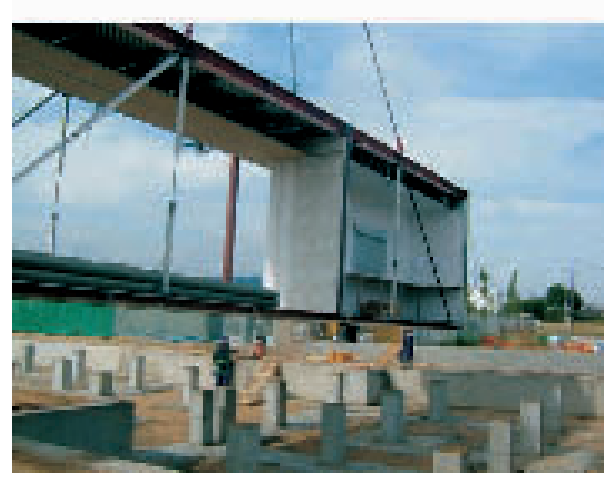

13. Axonometría del sistema.

14. Foto superior: fabricación de una escuela. Foto inferior: montaje de una escuela. Fotos de Oliva, J. M.

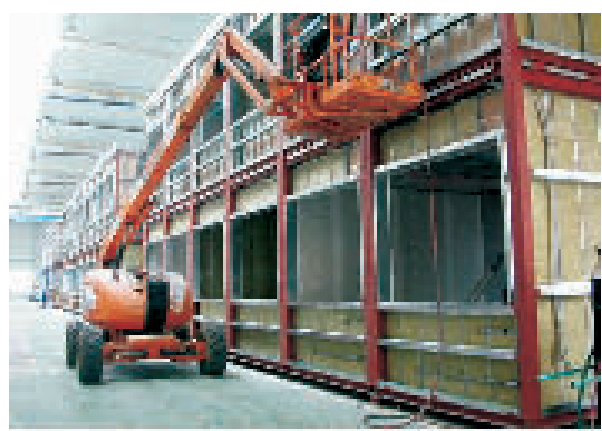

14

Las uniones estructurales se hormigonaron en la obra. La fachada estaba formada por paneles macizos autoportantes de $10 \mathrm{~cm}$ de espesor, fijados a los forjados con anclajes y tacos mecánicos (19).

\subsection{Sistema de estructura de módulos metálicos de medidas abiertas y componentes}

En los años 2000 se empezó a utilizar este sistema para prefabricar escuelas en nuestro país, el cual sigue vigente en la actualidad. La empresa "Modultec" había definido el sistema a principios de los años 1990 y en aquella década ya lo había utilizado para industrializar restaurantes, viviendas... En los años 2000 se han prefabricado varias escuelas en Castilla y León, Cataluña, Valencia... En Cataluña, de 2002 a 2006, se construyeron $79.000 \mathrm{~m}^{2}$ de CEIP públicos.

Este sistema utiliza una estructura de módulos metálicos con forjados de hormigón y fachada de componentes variables. Los módulos están formados por pilares tubulares de acero, vigas de perfiles laminados y un forjado mixto. Estos módulos se conectan en planta y altura mediante acoples, tornillos o soldaduras. Las fachadas pueden resolverse con cualquier tecnología industrializada disponible, como la cubierta, las instalaciones... (Fig. 13).

El conjunto del edificio con todas sus partes puede venir terminado desde fábrica. El montaje puede reducirse a resolver las juntas entre módulos con la lógica de la tecnología de cada una de las partes a rejuntar: fachada, cubierta... Por lo tanto, este sistema destaca porque las operaciones en la obra son mínimas. En cambio, la producción es artesanal y podría avanzar tecnológicamente con una mayor automatización (Fig. 14).

El CEIP Garigot de Castelldefels, Barcelona, es un ejemplo de escuela ejecutada con esta tecnología. Este fue encargado por el "DE", diseñado por "Nogué-Onzai-Roig Arquitectos". En 2005 "Modultec" construyó esta escuela de $3.332 \mathrm{~m}^{2}$ en 8 meses. La estructura estaba formada por 65 módulos. Estos tenían pilares tubulares cuadrados de $140 \times 140 \mathrm{~mm}$, vigas HEB 140 y forjados mixtos de $67 \mathrm{~mm}$ de canto. Los módulos tenían medidas variables, como por ejemplo 3,6 x 3,2 x 18,4 m. Las fachadas y las divisiones interiores se atornillaban a subestructuras de perfiles de acero galvanizado (20).

\subsection{Sistema de estructura de módulos metálicos de medidas prefijadas y componentes}

Este sistema se redefinió en los años 20022003, como una nueva versión de la tecnología "Caracola" de la empresa "Dragados", cuya primera versión data del 1972. A diferencia de otras versiones, este nuevo sistema estaba dirigido a la industrialización de edificios permanentes y permitía un mayor grado de flexibilidad de diseño. Con este sistema se construyeron gran cantidad de escuelas. Por ejemplo, en Cataluña, de 2002 a 2006 se prefabricaron unos $15.000 \mathrm{~m}^{2}$ de CEIP de carácter permanente.

La estructura del sistema estaba formada a través de la combinación de pórticos y módulos tridimensionales metálicos, con los forjados de losas de hormigón armado. La estructura estaba formada por perfiles de acero tubulares, HEB, IPN...Estos llegaban a la obra preparados para soldar y formar pórticos, o formando módulos que se colocaban y soldaban. Los módulos salían del taller con una cubierta provisional y el cerramiento de fachada, que era de paneles de GRC de $12 \mathrm{~mm}$ de espesor con bastidor de perfiles de acero. Las juntas entre paneles se sellaban con silicona y tenían mecanismos para la expulsión del agua que entrara accidentalmente (Fig. 15). El montaje podía durar unos seis meses incluyendo la estructura, la fachada y todas las otras partes.

Un ejemplo de escuela construida con este sistema es el CEIP "Can Roca" en Terrasa, Barcelona (Fig. 16). Este fue encargado por el "DE", diseñado por R. Alaminos y G. Vidal e industrializado en 2005 por "Drace". El edificio de primaria, de unos $2.300 \mathrm{~m}^{2}$, fue construido en 6 meses. La estructura de planta baja eran pilares, por ejemplo HEB 140, a los que se soldaban las vigas, que podían ser tubulares 100.100.5, y los forjados prefabricados: 
un marco metálico con correas sustentando una losa de hormigón armado de $45 \mathrm{~mm}$. En cambio la planta primera estaba formada por módulos metálicos de hasta 2,7 × 2,7 x 10,4 m. Estos módulos se componían del mismo tipo de estructura que la planta baja e incorporaban los paneles de fachada, todo ello prefabricado. En cambio, la cubierta, las divisiones interiores, las instalaciones, los acabados interiores... se ejecutaban en la obra por parte del mismo prefabricador y los industriales externos (21).

\subsection{Sistema de estructura de módulos metálicos plegables de medidas prefijadas y componentes}

A principios de los años 2000 la empresa "Algeco" empezó a utilizar este sistema para la construcción de centros docentes. El sistema se caracteriza por el uso de unos módulos metálicos plegables denominados "Plibat". En los años sesenta ya se habían utilizado sistemas similares como el "Terrapin" Británico (4). Pero en España es el primer sistema de estas características. Se empezó a utilizar para la construcción de pequeños edificios como guarderías y se fue extendiendo su uso en CEIP completos. En los centros de una sola planta, estos módulos metálicos plegables definían la estructura del edificio. Los módulos hacían hasta 2,4 x 3,6 x 9,6 m y estaban formados por los cuatro pilares y por una cubierta provisional. Los pilares, las vigas y las correas eran perfiles abiertos de chapa galvanizada conformados en frío, los cuales sustentaban una cubierta de chapa. En los edificios docentes de más de una planta la estructura era de pilares de perfiles semejantes a los de los módulos, pero que llegaban por separado a la obra. El forjado y la cubierta estaban formados de placas prefabricadas, compuestas de vigas, correas y una chapa de acero. En los forjados la chapa estaba hormigonada para formar un forjado mixto. Las fachadas eran de paneles prefabricados sándwich con la carpintería incorporada, los cuales se revestían por el interior y el exterior en la obra. El montaje de la estructura en edificios de una planta era muy rápido, ya que constaba del despliegue y la colocación de los módulos. EI resto del edificio lo montaban otros industriales, que colocaban en la obra la cubierta, los acabados interiores... (Fig. 17).
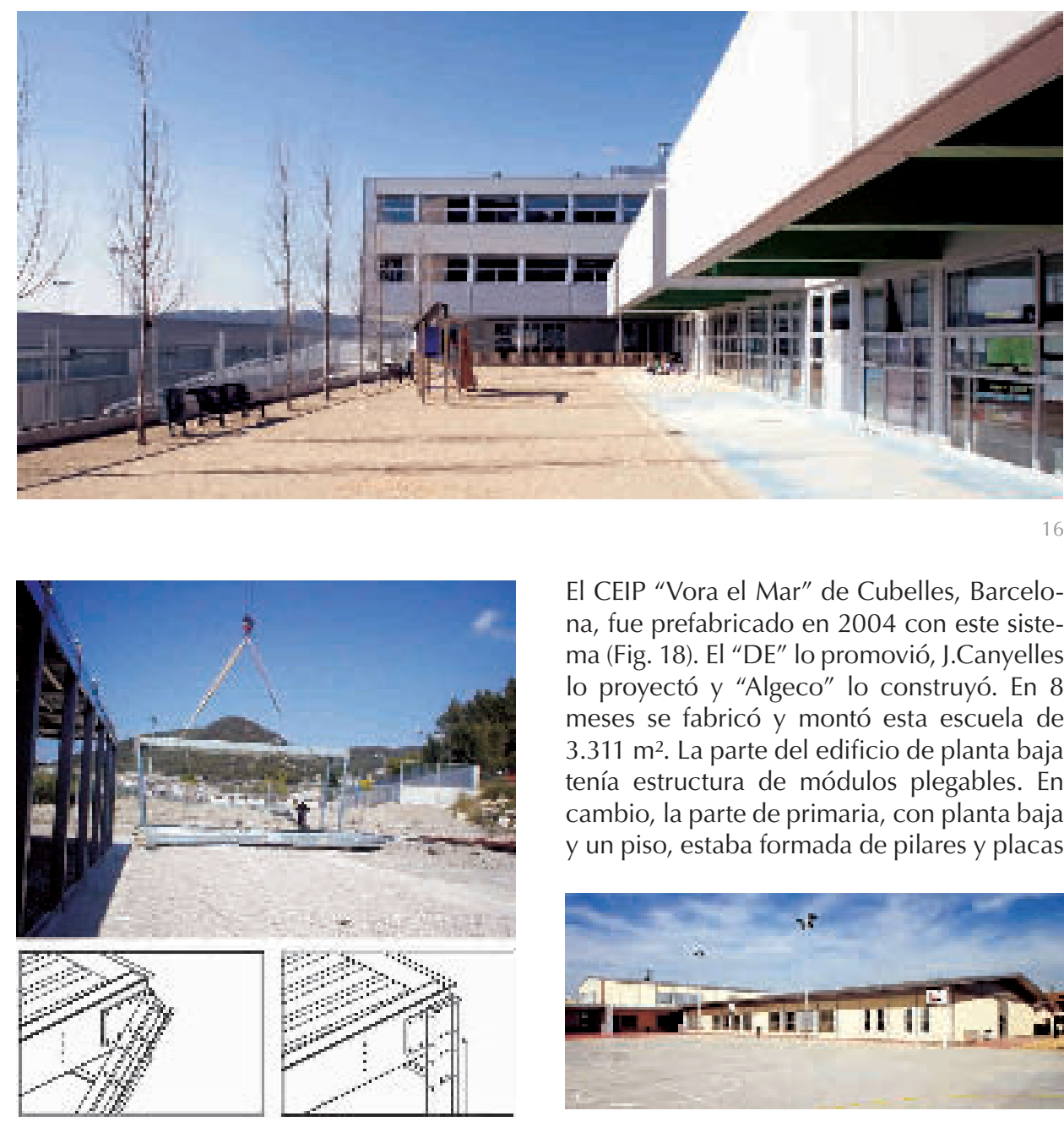

El CEIP "Vora el Mar" de Cubelles, Barcelona, fue prefabricado en 2004 con este sistema (Fig. 18). El "DE" lo promovió, J.Canyelles lo proyectó y "Algeco" lo construyó. En 8 meses se fabricó y montó esta escuela de $3.311 \mathrm{~m}^{2}$. La parte del edificio de planta baja tenía estructura de módulos plegables. En cambio, la parte de primaria, con planta baja y un piso, estaba formada de pilares y placas

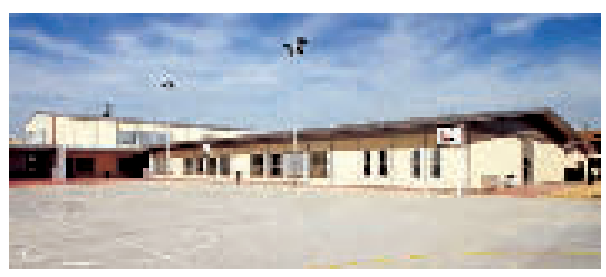

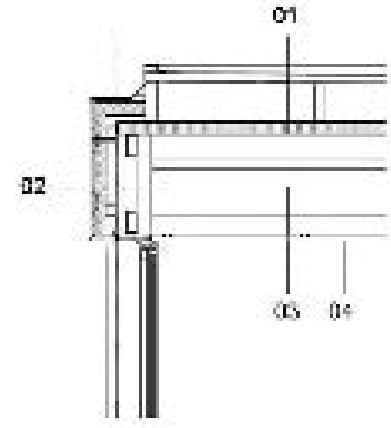

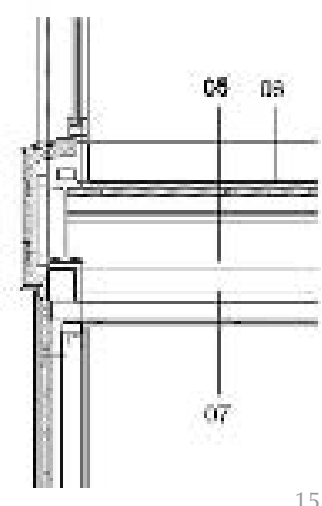

LEYENDA:

01. Cubierta definitiva del edificio encima de la cubierta provisional del módulo. Del exterior hacia el interior: lámina de PVC de $15 \mathrm{~mm}$ termosoldada; aislamiento de espuma de poliuretano de $3 \mathrm{~cm}$; chapa grecada prelacada; panel sándwich metálico de $4 \mathrm{~cm}$. 02. Panel de GRC de $12 \mathrm{~mm}$ soldado a bastidor metálico, con aislamiento posterior de lana de roca de $5 \mathrm{~cm}$. 03 . Vigas y correas de cubierta del módulo. Vigas en celosía formadas por cordones de perfiles tubulares (por ejemplo 80.40.3) y un redondo doblado de (por ejemplo f $10 \mathrm{~mm}$ ). Correas de perfiles tubulares.

04. Cielo raso de panel acústico de fibras vegetales de $25 \mathrm{~mm}$ con perfilería vista de omegas galvanizadas 30.20.30.

05. Forjado. Losa de hormigón armado de $45 \mathrm{~mm}$ con malla electrosoldada. Correas de IPN 80. Jácenas IPN 280. Ligado transversal de IPN 140.

06. Pavimento continuo de lámina vinílica de 1,2 mm por encima de lámina separadora.

07. Vigas y correas de cubierta de planta baja. Correa transversal de atado de pilares, por ejemplo 100.100.5 Correa transversal para la subestructura de fachada.
15. Detalle de este sistema (19).

16. Foto de una de las escuelas prefabricadas, cedida por "GISA" e "Imanagest".

17. Foto y detalles del montaje de una de las escuelas prefabricadas. Detalles de (20).

18. Foto de una de las escuelas prefabricadas, cedida por "GISA" e "Imanagest". 


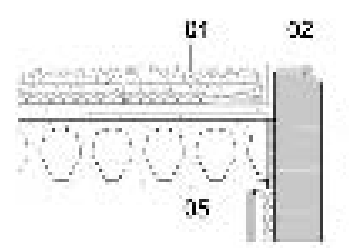

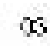

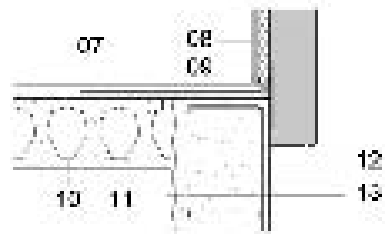

LEYENDA:

01. Cubierta plana transitable.

02. Chapa de aluminio de remate superior

03. Panel prefabricado de hormigón de $20 \mathrm{~cm}$ aligerado con EPS.

04. Aislamiento de lana de roca de $3 \mathrm{~cm}$.

$3 \mathrm{~cm}$.
05 . Trasdosado de placas de yeso laminado sobre perfiles de acero.

06. Aislamiento de lana de roca de $5 \mathrm{~cm}$.

07. Pavimento de PVC con lámina absorbente inferior.

08. Arrimador de DM pintado.

08. Arrimador de DM pintado.
09 . Zócalo de aluminio de $5 \mathrm{~cm}$.

10. Placa alveolar de hormigón pretensado.

11. Cielo raso de panel acústico de 11. Cie

fibras.

12. Viga pretensada de $40 \times 100$.

13. Trasdosado de placas de yeso laminado sobre perfiles de acero.
19. Detalle de este sistema. Detalle de (23).

20. Foto de una de las escuelas prefabricadas, cedida por "GISA" e "Imanagest".

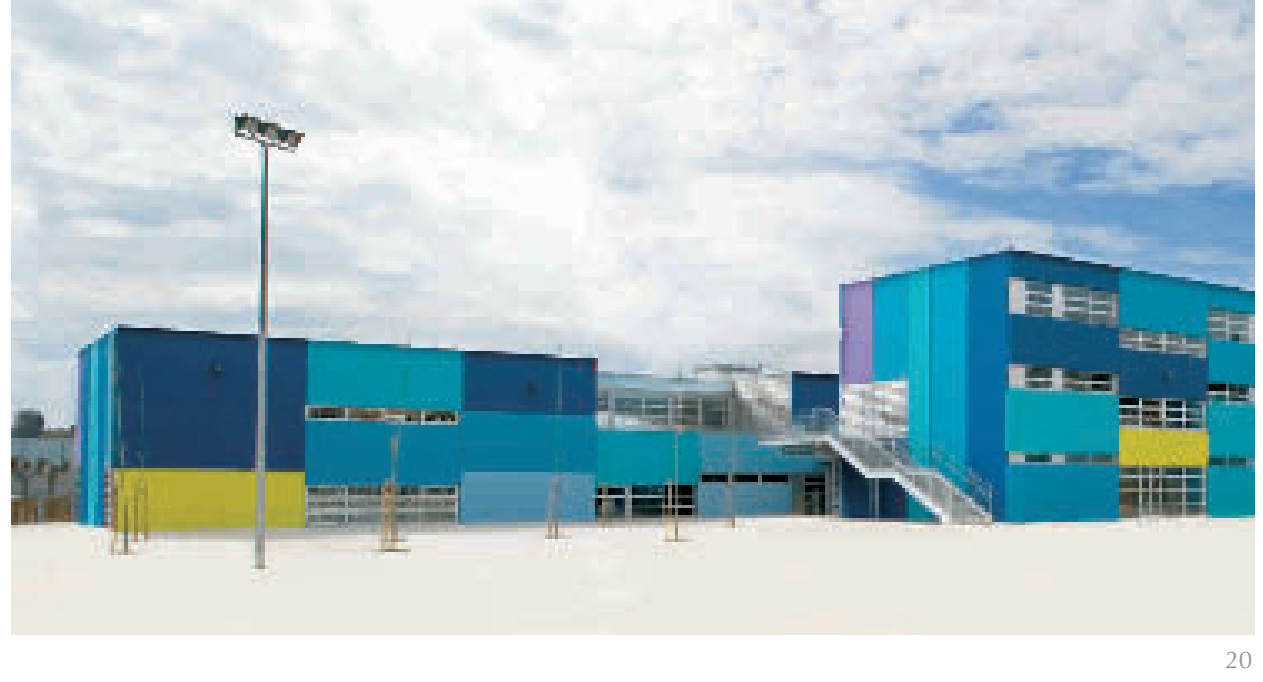

de forjado prefabricadas. La fachada era de paneles sándwich recubiertos en el exterior de hormigón polímero o chapa de aluminio. En el interior, había un trasdosado de placas de yeso laminado, atornillados a perfiles de acero. La cubierta definitiva era de baja pendiente, no transitable y vista (22).

En resumen, el sistema prefabricaba la estructura y la fachada para ser montados en la obra. Las otras partes del edificio se construían in situ.

\subsection{Sistema de módulos portantes, placas de forjado y paneles de fachada de hormigón prefabricado}

Entre los años 2003 y 2004 el Equip Arquitectura Pich-Aguilera y la prefabricadora "Pujol" emplearon por primera vez este sistema en unos edificios de viviendas plurifamiliares de Barcelona. En los años 1970 ya se había utilizado un sistema similar en Estados Unidos Ilamado "Mah-Le Mesurier" (3), pero en nuestro país fue una experiencia pionera. Entre 2002 y 2006 se construyeron 5 escuelas de grandes dimensiones, que sumaron $18.000 \mathrm{~m}^{2}$, todas ellas en Cataluña.

Actualmente se ha desestimado su uso por el elevado coste de los módulos de hormigón armado prefabricado. Estos módulos eran el elemento más significativo de la estructura de este sistema. Tenían sección en " $U$ " y unas dimensiones máximas de 2,4 x 3,26 × $6 \mathrm{~m}$. Soportaban el forjado de placas alveolares y las vigas de fachada, las uniones de las cuales se hormigonaban in situ, junto con la capa superior de hormigón armado. Las fachadas se resolvían en parte con paneles prefabricados de hormigón de $20 \mathrm{~cm}$ de espesor, que estaban aligerados con EPS en su interior. Estos paneles se unían a las vigas perimetrales con angulares metálicos atornillados. Las juntas entre estos se sellaban con silicona y estaban drenadas para expulsar la entrada indeseada de agua (Fig. 19). Las otras partes del edificio se construían en la obra por parte de industriales externos: cubierta, instalaciones, acabados interiores...

Una de las 5 escuelas prefabricadas con esta tecnología es el CEIP "Àngels Alemany" de Lloret de Mar, Girona (Fig. 20). Éste fue encargado por el "DE" en 2005, diseñado por Equip Arquitectura Pich-Aguilera y montado por "Pujol". Se construyó en 7 meses con módulos de medidas variables y alveolares de hasta $11,5 \mathrm{~m}$ de largo y 30 de canto con capa de $5 \mathrm{~cm}$.

Los paneles tenían el acabado liso de molde y se pintaron en la obra. Los otros elementos no dependían del sistema. Por ejemplo, la cubierta era plana, transitable y oculta; y los trasdosados y las divisiones interiores eran de yeso laminado sustentado por un entramado metálico (23). La estructura y la fachada estaban prefabricadas y montadas en la obra, mientras que las otras partes, más o menos industrializadas, se construían en el solar.

\subsection{Sistema de muros portantes macizos y placas de forjado de hormigón prefa- bricado}

Este es un sistema que se ha utilizado para prefabricar gran cantidad de viviendas plurifamiliares desde finales del siglo pasado, cuando la empresa "Indagsa" definió esta tecnología. Es un sistema similar al "3.3" pero con los muros portantes de una sola capa de hormigón y más flexibilidad de formas y de tipos de forjado. Su uso para centros docentes ha sido anecdótico: por ejemplo, en Cataluña sólo se han prefabricado 2 centros docentes utilizando este sistema.

Se compone de muros estructurales macizos y forjados diversos más o menos prefabricados. Los muros son portantes o de arriostra- 
miento, miden de 12 a $20 \mathrm{~cm}$ de espesor, y pueden hacer hasta unos 3,5 x $10 \mathrm{~m}$. Los que están en el exterior del edificio forman la hoja exterior de la fachada y pueden tener diversos tipos de acabado: liso para pintar, con el árido visto, lavado con chorro de arena... Los forjados pueden ser varios: placas alveolares, pre-losas, viguetas... (24).

Las uniones entre paneles se resuelven soldando unas pletinas puntuales y rellenando las juntas con mortero de baja retracción. Las uniones entre paneles y forjado son hormigonadas y pueden tener ménsulas lineales para soportar el cortante desde el montaje. Las juntas entre paneles se sellan con silicona por la cara exterior, tienen el mortero de la unión por la cara interior y un sistema de drenaje para expulsar posibles filtraciones (Fig. 21) (24). El CEIP "Vinya del Sastret" de Sant Esteve Sesrovires, Barcelona, es un ejemplo de escuela construida con este sistema (Fig. 22).

Este fue encargado por el "DE", diseñado por J.A. de Alonso y J. Abulí, y prefabricado en 2005 por "Indagsa". En 7 meses se fabricó y montó esta escuela de $3.100 \mathrm{~m}^{2}$. La estructura estaba formada por paneles prefabricados macizos de hormigón. Los paneles portantes tenían un espesor de $14 \mathrm{~cm}$ y los de arriostramiento de $12 \mathrm{~cm}$. El forjado estaba resuelto por placas alveolares de $30 \mathrm{~cm}$ de canto con una capa de compresión de $5 \mathrm{~cm}$. Los paneles tenían un acabado con chorreado de arena.

La cubierta, interiores, instalaciones y demás partes se construyeron en el solar por parte de distintos industriales ajenos a este sistema prefabricado (25).

En resumen, con este sistema sólo el cerramiento de fachada y la estructura son prefabricados en el taller y montados en la obra. Las otras partes se construyen in situ.

\section{EL FUTURO DE LAS TECNOLOGÍAS DE PREFABRICACIÓN}

En este artículo se ha hecho un breve recorrido por el pasado y el presente de la prefabricación de escuelas en nuestro país, el cual nos permite extraer conclusiones sobre la evolución de estas tecnologías aplicadas a la arquitectura escolar.

5.1. Las tecnologías actuales, en comparación con los sistemas previos de los años 1970, destacan por haber adquirido una flexibilidad que les permite:

- Solucionar proyectos de arquitectura respetuosos con el solar, la trama urbana, el contexto cultural, el entorno paisajístico...
- Solventar en cada proyecto sus espacios interiores y exteriores, que pueden ser adaptaciones singulares del "programa funcional estándar de una escuela".

- Ser compatibles con otras tecnologías. Esta flexibilidad posibilita que un mismo sistema prefabrique el conjunto del edificio o sólo una parte. Pero actualmente, las uniones y las juntas entre los sistemas estudiados están en proceso de desarrollo.

Esta flexibilidad es el resultado de una evolución hacia la prefabricación abierta y a medida, distinta de la prefabricación cerrada de los sistemas precedentes. Esta prefabricación adaptable a cada usuario se apunta como el futuro desde algunas teorías actuales de la arquitectura industrializada (26).

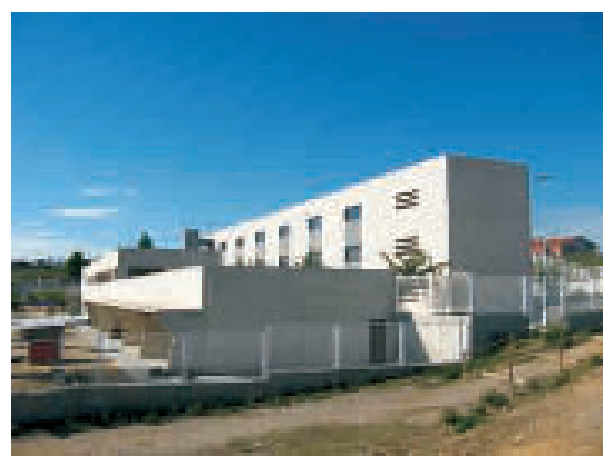

21. Arriba: unión estructural y junta de estanqueidad entre paneles. Abajo: unión entre el panel y el forjado. Detalles facilitados por "INDAG, S.A.U."

22. Foto de una de las escuelas prefabricadas.

\subsection{En cambio, las tecnologías de prefa- bricación actuales tienen otros aspec- tos pendientes de mejorar}

- El número de operaciones a pie de obra necesarias para construir con los sistemas actuales es semejante al de los sistemas pretéritos. Sólo se ha reducido significativamente en uno de los sistemas ligeros actuales: el "4.2". En el periodo entre 1970 y la actualidad, la tecnología de muchas disciplinas se ha robotizado, pero la construcción prefabricada se ha automatizado poco y la mayoría de operaciones siguen siendo a pie de obra. Una excepción son las edificaciones móviles estándar: aularios, casitas de obra, "motorhome" (27). Aunque estas tecnologías cerradas tienen resultados alejados de lo que se entiende actualmente por arquitectura.

- La incorporación de novedades o cambios es lenta. Por ejemplo, estas tecnologías aún están en proceso de mejorar su impacto ambiental. En este sentido, algunas tecnologías de los años setenta no fueron capaces de adaptarse a las necesidades del momento, lo cual fue una de las causas de su fracaso. 


\subsection{En la evolución de estas tecnologías se desconocían las experiencias previas}

- En la definición de nuevos sistemas o en la redefinición de sistemas existentes se han obviado las experiencias anteriores. La mayoría de estos sistemas y de los edificios resultantes están pendientes de catalogación y estudio. Tampoco se han realizado operaciones necesarias de: mantenimiento, rehabilitación, desmontaje...

\subsection{En resumen, para el futuro de las tec- nologías de prefabricación se aconseja}

- Continuar avanzando hacia una prefabricación flexible y adaptable al proyecto.

- Disminuir las operaciones en la obra y automatizar los procesos productivos.

- Agilizar la actualización de los sistemas para incorporar novedades o cambios.

- Elaborar un compendio de buenas soluciones mediante el estudio de cada tecnología y el análisis del ciclo de vida de sus edificios (construcción, uso, mantenimiento, desmontaje, reutilización...).

\section{BIBLIOGRAFÍA}

(1) Pons, O.: "Arquitectura escolar prefabricada a Catalunya", ETSAB, UPC, Barcelona, 2009. Director de tesis: González, J.M.

(2) Garcia, R.: "Escuelas prefabricadas en el Campo de Gibraltar". Revista Nacional de Arquitectura. 180, 7-8. 1956

(3) Seminario de Prefabricación: "Prefabricación, Teoría y Práctica". 2 Tomos. Barcelona: Editores Técnicos Asociados, 1974.

(4) Russell, B.: "Building systems, industrialization and architecture". John Wiley \& Sons, London, 1981.

(5) Ministerio de Educación y Ciencia: "Programa de construcciones escolares industrializadas". Aro Artes Gráficas Editorial, Madrid, 1979.

(6) Mateo, J. L.; Bosch, C. et al.: "Caracola Edificaciones Modulares". Informes de la construcción. 297, 45-71. 1978

(7) Avellaneda, J.: "Arquitectura escolar a Catalunya: 1990-2001". Generalitat de Catalunya, Departament d'Ensenyament, Direcció General de Centres Docents, Barcelona, 2003.

(8) "Mostra d'arquitectura escolar". Generalitat de Catalunya, Dep. d'Ensenyament, Barcelona, 1986.

(9) Pich-Aguilera, F.; Brufau, R.: "Indústria i Arquitectura - Nous processos d'industrialització al servei de l'arquitectura". Escola Sert, COAC, Barcelona, 2005.

(10) Expediente de licencia de apertura de establecimiento y ejercicio de actividades instado por "Durisol, SAE" para legalización de industria. Archivo Municipal de Sant Vicenç dels Horts, 1975.

(11) "Introducción a la construcción modular de edificios escolares". Catálogo de la empresa ModulTeu. Publiartigas. Barcelona, 1968.

(12) Proyecto del Grupo Escolar "Can Clos". Ayuntamiento de Barcelona. Unidad Operativa de Edificios Municipales. Archivo Municipal Administrativo de Barcelona, 1969.

(13) Construcción Industrial de Edificios, SA. CIDESA. 197x.

(14) ModulBeton, SA: "Catálogo comercial de la empresa ModulBeton". 1974.

(15) "Sanqui 1953-1978. 25 años de vocación empresarial". Información sobre la empresa y el sistema constructivo. Madrid, 1978

(16) Walker, H. C.: "PCl manual design of connections for precast prestressed concrete". 1973, PCI.

(17) "Structural Connections for precast concrete buildings, guide to good practice prepared by Task Group 6.2", C.E.B.- F.I.B., Lausanne, 2008.

(18) Catálogo técnico de Prefabricats Planas SAU. 2007.

(19) BRD Architects. Proyecto ejecutivo del CEIP "Ca n'Alzamora" en Rubí. 2005.

(20) Nogué-Onzai-Roig Arquitectos: "Proyecto ejecutivo del CEIP Garigot en Castelldefels". 2005.

(21) Alaminos, R.; Vidal, G.: "Proyecto ejecutivo del CEIP Can Roca en Terrassa". 2005.

(22) Canyelles, J.: "Proyecto ejecutivo del CEIP Teresina Martorell en el Vendrell". 2005.

(23) Equip Arquitectura Pich-Aguilera: "Proyecto ejecutivo CEIP Àngels Alemany", Lloret de Mar. 2005.

(24) Sistema de paneles prefabricados portantes INDAGSA de hormigón armado. Dit 452. Madrid: Instituto Eduardo Torroja.

(25) De Alonso, J. A.; Abulí, J.: "Proyecto ejecutivo CEIP Vinya del Sastret", Sant Esteve Sesrovires. 2005.

(26) Kieran, S.; Timberlake, J.: "Refabricating architecture: How manufacturing methodologies are poised to transform building construction". McGraw-Hill Professional, 2004.

(27) Davies, C.: "The Prefabricated Home". Reaction Books, London, 2005. 